\title{
Current View of the Budd-Chiari Syndrome Clinical Approach
}

\author{
Angélica Sabino Pereira Rodrigues*, Isabelle Costa Gualberto Rosalino, João Vitor Emidio \\ Oliveira and Brian França dos Santos
}

Gastroenterology and Digestive System Surgery Academic League at Iguaçu University - UNIG - Medicine School, Brazil

*Corresponding author: Angélica Sabino Pereira Rodrigues, Gastroenterology and Digestive System Surgery Academic League at Iguaçu University - UNIG - Medicine School, Brazil.

To Cite This Article: Angélica Sabino Pereira Rodrigues, Isabelle Costa Gualberto Rosalino, João Vitor Emidio Oliveira, Brian França dos Santos. Current View of the Budd-Chiari Syndrome Clinical Approach. 2020 - 11(1). AJBSR.MS.ID.001603. DOI: 10.34297/AJBSR.2020.11.001603.

Received: 阱 November 17, 2020; Published: 制 December 08, 2020

\begin{abstract}
The Budd-Chiari Syndrome (SBC) was first mentioned in 1845 by George Budd, a British physician who associated liver thrombosis with liver abscess, and then in 1899 by Hans Chiari, an Austrian pathologist, who delimited a clinical and pathological condition relating to the disease of primary obliterative endophlebitis. The disease became known as Budd-Chiari syndrome [1-3]. The Budd-Chiari syndrome is a rare disease in which obstruction of the hepatic veins occurs, which can be thrombotic or non-thrombotic, thus leads to a progressive centrilobular liver retention, resulting in cirrhosis $[1,4]$. This thrombus can occur anywhere in the venous pathway, from the hepatic venules to the junction of the inferior vena cava to the right atrium [1]. The causes that determine SBC include coagulation abnormality, trauma, tumor extension (neoplasia) or obstructive congenital abnormalities (thrombophilia) [3]. SBC is classified as primary or secondary. In the primary, which has a rare condition, there is a obstruction of the hepatic flow that results from endovascular injury, such as thrombus, membranes or phlebitis. In the secondary it involves pathologies extrinsic to the vascular system, which blocks the flow of the flood by compression [1,2]. In order to diagnose the syndrome, clinical evaluation and image evaluation are required, such as color doppler ultrasonography, computed tomography or magnetic resonance imaging. Confirmation requires a liver biopsy, which is conclusive in rare forms of the disease, such as cirrhosis [1]. The treatment must be individualized and thorough, performing a good physical examination on the patient, carefully analyzing the images of the tests, as every detail will be important for the therapeutic conduct $[1,2,4]$.
\end{abstract}

Keywords: Hepatic Obstruction of Venous Flow, Etiology, Treatment, Diagnosis, Pathogenesis

\section{Objective}

The objective of this work is to review the Budd-Chiari Syndrome, clarifying the importance of knowing the disease, such as its etiology, epidemiology, diagnosis and treatment in a more clinical perspective.

\section{Methods}

This is a bibliographic review researched in the databases of the Virtual Health Library (VHL), Scientific Electronic Library Online (SciELO) and Google Scholar. We used as criteria of inclusion articles published from the year 2016 to 2020. A full text filter was used, among them written in Portuguese, Spanish and English.

\section{Literature Review}

The SBC is an uncommon disease, found in both genders, and it can occur at any age, but it is more common from 30 to 40 years old. It occurs in 1/100,000 of the general population worldwide $[1,3]$. It can occur in 4 ways: fulminant, acute, subacute or chronic. The fulminant form is the rarest and is characterized by hepatic encephalopathy, which can appear up to eight weeks after the onset of jaundice. In the acute form, we have the formation of untreatable ascites. The subacute form is the most common and occurs with progressive ascites and minimal hepatocellular injury. And in chronic form, when the patient has liver cirrhosis [2]. The SBC is etiologically divided into primary and secondary. The primary is caused by the obstruction of venous blood flow by thrombi or inflammation, and the secondary is caused by compression or invasion of the inferior vena cava or the hepatic vein by lesions originated outside these vessels, such as neoplasms and abscesses $[1,2,4,9]$. 
The primary SBC can manifest in patients with myeloproliferative hematological disorders, polycythemia vera, primary myelofibrosis or in patients who have hypercoagulable conditions $[2,7]$ caused by mutations in coagulation factors or a protein $\mathrm{C}$ deficiency. Other risk factors related to etiology are pregnancy and oral contraception, due to the increased risk of these patients developing thrombosis. Therefore, the request for a hematological laboratory test is indicated to all patients in order to exclude secondary etiology of SBC. On the other hand, secondary SBC is caused when the hepatic vein or the inferior vena cava are compressed or invaded by lesions that obstruct the vessels and generate consequent thrombosis. These obstructions can be caused by cysts, abscesses, carcinomas and even trauma [5]. There has also been reported SBC due to renal catheter deviation in a patient with chronic kidney disease on hemodialysis but hematological tests were not performed to determine whether thrombophilic factors contributed to trigger a venous thrombosis [8]. Initially, the pathophysiology of SBC is the blood obstruction between the hepatic veins and the supra or infra-hepatic segment of the inferior vena cava. However, the clinical manifestation of the disease depends on whether both veins are obstructed, either primary or secondary [1]. This obstruction triggers hemodynamic changes in the liver that increases the portal capillary hydrostatic pressure, which alters vascular pressure gradients [9]. These changes result in an increase in intra sinusoidal pressure due to dilation of the sinusoids and the leakage of fluids into the interstitial space. The hepatic perfusion through this vein decreases, causing hepatocyte lesions due to cellular hypoxia, resulting in liver fibrosis and in the long term it can cause liver cirrhosis [5].

\section{Discussion}

The Budd Chiari Syndrome is a rare disease that is difficult to diagnose with little-known causes, characterized by a set of macroscopic and microscopic manifestations in which portal hypertension is present in most cases. Knowing the entire anatomy of liver drainage and perfusion, it is known that if there is an obstruction at the level of the venules or the inferior vena cava, the blood ends up being impacted in the liver causing a hepatomegaly. Due to the rapid growth, the capsule that surrounds the liver is unable to keep up leading to the onset of pain. This syndrome is clinically characterized by hepatomegaly triggered by venous obstruction of the hepatic drainage system, which may be primary or secondary, tending to be diagnosed when complications are already well established, whether acute or chronic progressing to a termination stage in which the transplantation ends up being the only alternative $[1,2,4]$. Due to its pathophysiology, which is still quite dismal, most of the events that are triggered are due to thromboembolic phenomena generated from portal hypertension that ends up leading to pathological parenchymal death phenomena observed in histopathology, such as ischemic necrosis areas and intense apoptosis areas that end up remodeling the liver architecture. In addition to hepatocytes in general, sinusoid capillary endothelial cells are also important for this pathogenesis, as Virchow's Triad shows, since chronic hypoxia also leads to necrosis of these cells, triggering inflammatory and thrombotic conditions [9]. The little current understanding is basically due to the fact that the diagnosis is established when the patient already has complications, such as esophageal varices and other thromboembolic events that, despite being acute, present a moderate rate of reversion, or complications in which the individual almost always evolves for death, such as acute liver failure and even cirrhosis [10]. Like the other parenchymal or vascular diseases of the liver, we are increasingly observing that a thorough anamnesis accompanied by a physical examination is essential to think about SBC. But of course, given this syndrome, only these two points are not enough, signaling the importance of complementary exams. In addition to complementary exams such as Doppler ultrasound to confirm the presence or not of thrombi adhered to the endothelium of the liver drainage system, this exam is also valid for identifying cirrhosis in which it will be confirmed by histopathological examination by a biopsy. Other imaging tests such as Computed Tomography and Magnetic Resonance have also been shown to be effective in identifying SBC [1].

The syndrome causes include changes in Virchow's Triad, with hypercoagulability being the most characteristic as been evidenced by literature. The Budd Chiari syndrome is most often accompanied by myeloproliferative syndromes but other causes may also be included such as antiphospholipid syndrome, Behçet's disease, antithrombin III, protein C and S deficiency, use of contraceptives associated with one of the previous conditions, as well as more rare cases such as malignant neoplastic lesions and even extrahepatic tumors with progressive evolution [2]. Based on the latest publications in which it is shown that the histopathological examination is extremely necessary for this syndrome, we see that the changes observed at the macroscopic level correspond to his histopathological changes. That very congested, pale piece with more rhomboid edges due to hepatomegaly itself shows a perivenular blood congestion due to thrombosis which culminates in the collapse of the hepatic architecture progressively rendering the occluded centrilobular veins, with their red blood cell free light, seen that in this situation the majority are present in the space of Disse. When the assessment focuses on a more progressive condition, we see that the thrombi tend to be recanalized, in which about $30 \%$ of patients are followed according to the progression of the pathogenesis - this condition progresses until the formation of thrombi in the inferior vena cava, where symptomatology tends to become more and more evident [9]. Even the asymptomatic majority, when in a more advanced stage these patients tend to manifest clinically with pain in the right hypochondrium and complaining of dyspnea triggered by bulky ascites that tends to 
compress the diaphragm resulting in respiratory signs, these patients do many phenomena of pulmonary embolism, where jaundice tends to be mild at the beginning of the disease. The edema tends to be characteristic of the lower limbs confirmed by the locker signal and also by the formation of collateral circulation of the vena cava type due to the pathogenesis previously mentioned [11]. Thus, in its minority it presents itself as a fulminant condition where the submassive collapse of the hepatic architecture is often accompanied by a reduction in the levels of consciousness due to the reduction of the hepatic metabolic activity (hepatic encephalopathy) in which the treatment of intrahepatic shunt, portosystemic, transjugular and other shunts are essential for the treatment - remembering that as mentioned in the references, the initial clinical approach supported by pharmacology is necessary with anticoagulants unless the patient does not present contraindications.

According to some published articles, it also shows that when there are signs of liver failure, shunt is no longer an alternative, since it showed that their patients presented a worsening after its performance, being indicated in this situation the liver transplant that has a strong curative action. In genetic factor coagulopathies but careful monitoring through the initial approach is not ruled out, that is, the use of anticoagulants $[1,4,11]$.

\section{Final Consideration}

The research on Budd Chiari Syndrome sought a recent clinical approach showing the importance of various medical specialties for early diagnosis and treatment in order for these studies to show a markable improvement in prognosis when it comes to a thorough and detailed physical examination, not only to cover primary liver disease but also its complications. The syndrome, a little recent compared to other liver diseases in the matter of studies, raised several questions that are still under study, but that served as a basis for discussing the importance of physical examination for an accurate and clear diagnosis of these patients, which was not a reality found in recent years.

\section{References}

1. Gaviria SC, Ramírez AC, Herrera YPE, Gutiérrez JCR (2016) Síndrome de Budd-Chiari: revisión de tema. Rev Col Gastroenterol 31(3): 242- 252.

2. Jiménez CE, Randial L, Silva I, Alférez F (2019) Tratamiento endovascular del síndrome de Budd-Chiari, a propósito de un caso. Rev Colomb Cir 34(4): 386-393.

3. Cole LJ (1960) Budd-Chiari Syndrome. Canad M A J 83: 813-818.

4. Ferreira J, Mieres M, Rivero F, Elizondo M, Facal J (2019) Síndrome de Budd-Chiari asociado a síndrome antifosfolípido. Ver Méd Urug 35(1): 60-66

5. Grus T, Lambert L, Grusová G, Banerjee R, Burgetová A (2017) BuddChiari Syndrome. Prague Med Rep 118(2-3): 69-80.

6. Simón CG, Ramírez AC, Espinoza HYP, Restrepo G JC (2016) A Review of Budd Chiari Syndrome. Rev Col Gastroenterol 31(3): 242-252.

7. Araujo GN, Restelatto LM, Prompt CA, Karohl C (2017) Síndrome de Budd-Chiari secundária a trombose de veia cava inferior associada a cateter. J Bras Nefrol 39(1): 91-94.

8. Araujo GN, Restelatto LM, Prompt CA, Karohl C (2017) Budd-Chiari syndrome secondary to catheter-associated inferior vena cava thrombosis. J Bras Nefrol 39(1): 91-94.

9. Bogliolo_Patologia_Geral pp: 50.

10. Beltrán ORM, Rodríguez JJS, Ramírez RDM, Carreño JMV, Escobar FEN (2017) Síndrome de Budd-Chiari agudo secundario a cirrosis alcohólica. Manejo intervencionista y descripción de uma complicación. Rev Colomb Radiol 28(4): 4821-4824.

11. Garcia-PJC, Buscarini E, Janssen HLA, Leebeek FWG, Plessier A, et al. (2016) Recomendações de Orientação Clínica EASL: Doenças vasculares hepáticas. Journal of Hepatology 64: 179-202. 